\title{
Aflatoxins contamination in chilli samples from Pakistan
}

\author{
R. Russell M. Paterson * \\ Micoteca da Universidade do Minho, Centro de Engenharia Biológica, Campus de Gualtar, 4710-057 Braga, Portugal
}

Received 14 January 2006; received in revised form 10 April 2006; accepted 17 April 2006

\begin{abstract}
The aim of this study was to prioritise disease and pest constraints in chilli by highlighting aflatoxin concentrations to assist local farmers in control. All samples contained aflatoxin $B_{1}$ and high levels were obtained from all ground samples. A direct relationship was observed between aflatoxin $\mathrm{B}_{1}$ and aflatoxin $\mathrm{B}_{2}$ concentrations. There was no relation between aflatoxin and Aspergillus flavus detection. Chilli production in Pakistan may be heavily constrained by aflatoxin contamination. Simply removing $A$. flavus may be insufficient for control. Aflatoxins from chilli may be a threat to the health of populations and a constraint on development in Pakistan.

(c) 2006 Elsevier Ltd. All rights reserved.
\end{abstract}

Keywords: Chilli; Aflatoxin; Aspergillus; Pakistan

\section{Introduction}

Mycotoxins are from fungi which contaminate foodstuff (CAST, 2003; Venâncio \& Paterson, in press). Aflatoxins are the most serious and well-known examples: Aflatoxin $\mathrm{B}_{1}$ is the most toxic. Aspergillus flavus may be the predominant producer of the B group. Furthermore, it is important to differentiate between natural contamination levels in crops and those which may be present from malicious intent in the current security conscious age (Paterson, in press-a).

As per the recently introduced European Union (EU) regulations, only $5 \mu \mathrm{g} \mathrm{kg}^{-1}$ of aflatoxin $\mathrm{B}_{1}$ and $10 \mu \mathrm{g} \mathrm{kg}^{-1}$ of total aflatoxins are allowed in chillies. Pakistan and the United States of America do not have any regulations for this commodity. However, the mycotoxin problem is most acute in developing countries where climate and lack of resources compromise production. The drive for exports to raise revenue and strict regulations in developed countries means that the best quality commodities are sold leaving the remainder, which have higher toxin concentra-

\footnotetext{
* Tel.: +351 253604 400; fax: +351 253678986 .

E-mail address: russell.paterson@deb.uminho.pt
}

tions as a consequence. Such problems exist for chillies (e.g. Bhat, 1988). Chillies are produced and consumed in developing and developed countries. For example, curries are virtually the national dish of the United Kingdom.

A. flavus was reported to have obtained from chillies from Pakistan in Shamshad, Zuberi, and Qadir (1985). However, otherwise relevant information is severely limited. Reddy, Kiran Mayi, UmaReddy, Thitumala-Devi, and Reddy (2001) analysed the pods and powders of chillies from India and found high levels of $\mathrm{AFB}_{1}$, particularly in lowest grade pods. Ravi Kiran, Narayana, and Vijayalakshmi (2005) only analysed one sample which was misleading, as it was in fact a survey of fungi. In addition, a survey of chillies was undertaken where high levels were reported in a few cases (UK Food Standards Agency, 2005). There is no information on aflatoxins concentrations in chillies from Pakistan.

The National Master Agricultural Research Plan - 19962005 - for Pakistan identified chillies as a crop which requires research to increase and stabilise yield and quality (PARC, 1996). In Pakistan, chilli harvest begins in the middle of July and ends in November. Red chilli is sun dried for 3-7 days or until the material is $33 \%$ of its fresh mass leaving considerable scope for moisture accumulation at some stages, which is conducive to the growth of aflatoxigenic 
fungi. Drying involves spreading of one layer thick pods on the soil. Sorting is sometimes undertaken to remove the damaged and diseased chillies, but it is rudimentary. There is considerable room for process control as detailed in the discussion of the present paper.

The current document provides in a timely manner, and with a view to assist local farmers, data on the levels of aflatoxins in red chillies produced in Pakistan. The author was responsible for the analysis in the preliminary report (Smith, Hamid Makhdum, \& Ahmad, 2000) when an EU limit for chillies had not yet been set.

\section{Materials and methods}

Dried chilli samples of various unrecorded weights of whole pods and powder were obtained directly from markets in Pakistan as sold by the vendors (Table 1). A. flavus strains were isolated by serial dilutions onto Malt Agar (Malt extract (Whitbread Ltd.) $20 \mathrm{~g}$; Oxoid agar No 3 $20 \mathrm{~g}$; Tap water to 11 ).

The samples were further powdered where necessary and analysed using standard HPLC methodology in accordance with the R-Biopharm Rhone Ltd., Glasgow, Scotland company leaflet, Instructions for use for EASIEXTRACT aflatoxins immunoaffinity columns (IAC). Fifty g of ground sample was blended with $200 \mathrm{ml}$ of acetone:water at a ratio of $80: 20$ for $3 \mathrm{~min}$. After filtration (Whatman 2V), $4 \mathrm{ml}$ of the filtrate was diluted with $132 \mathrm{ml}$ of PBS before cleanup using Easi-Extract aflatoxin immunoaffinity columns (R-BioPharm). Aflatoxins were eluted with methanol and quantification was carried out by HPLC (JASCO) using a Spherisorb ODS1 HPLC column $(250 \times 4.6 \mathrm{~mm})$, mobile phase of WAM (water/acetonitrile/methanol 6:3:1). Post column derivatisation (bromination) was carried out using a KOBRA electrochemical cell and subsequent detection was achieved using a fluorescence detector. Data were acquired and converted from analogue to digital using a Nelson instrument and PC Int software was used to analyse the data.

Table 1

Description of the chilli samples used in this study

\begin{tabular}{lllll}
\hline $\begin{array}{l}\text { Sample } \\
\text { number }\end{array}$ & Sample & Location & $\begin{array}{l}\text { Aspergillus } \\
\text { flavus }(\mathrm{cfu})\end{array}$ & $\begin{array}{l}\text { Total aflatoxin } \\
\left(\mu \mathrm{g} \mathrm{kg}^{-1}\right)\end{array}$ \\
\hline 1 & $\mathrm{G}$ & Karachi & 0 & 96.2 \\
2 & $\mathrm{G}$ & Islamabad & 0 & 66.1 \\
3 & $\mathrm{G}$ & Islamabad & $10^{3}$ & 61.3 \\
4 & $\mathrm{G}$ & Islamabad & $10^{3}$ & 48.9 \\
5 & $\mathrm{G}$ & Faislabad & 0 & 46.8 \\
6 & $\mathrm{G}$ & Islamabad & 0 & 40.1 \\
7 & $\mathrm{G}$ & Lahore & $10^{4}$ & 34.3 \\
8 & $\mathrm{G}$ & Lahore & 0 & 25.5 \\
9 & $\mathrm{G}$ & Faislabad & $9 \times 10^{2}$ & 6.8 \\
10 & $\mathrm{P}$ & Peshwar & $2 \times 10^{2}$ & 6.6 \\
11 & $\mathrm{P}$ & Karachi & $6 \times 10^{2}$ & 1.7 \\
12 & $\mathrm{P}$ & Lahore & 0 & 0.2 \\
13 & $\mathrm{P}$ & Lahore & $2 \times 10^{0}$ & 0.1 \\
\hline
\end{tabular}

$\mathrm{G}=$ ground and $\mathrm{P}=$ pod samples.

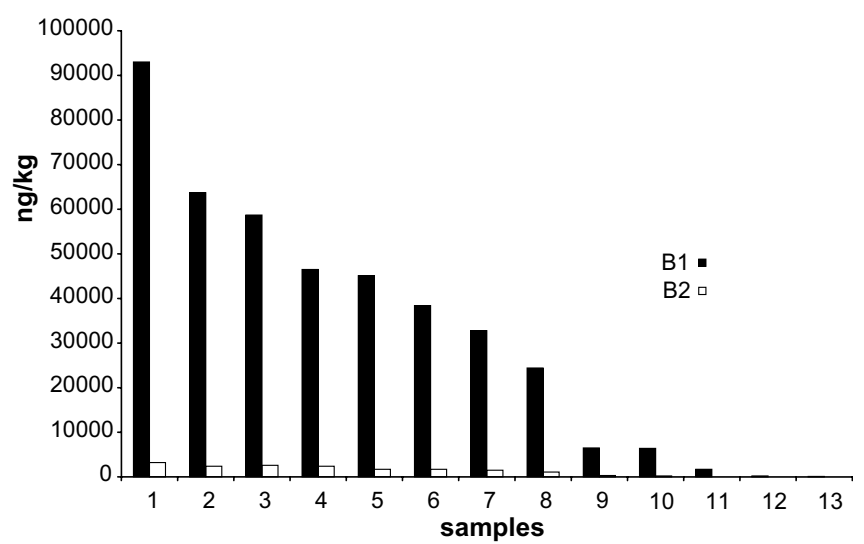

Fig. 1. Aflatoxin concentrations from chilli samples. Samples $1-9$ are powdered and 10-13 are pods.

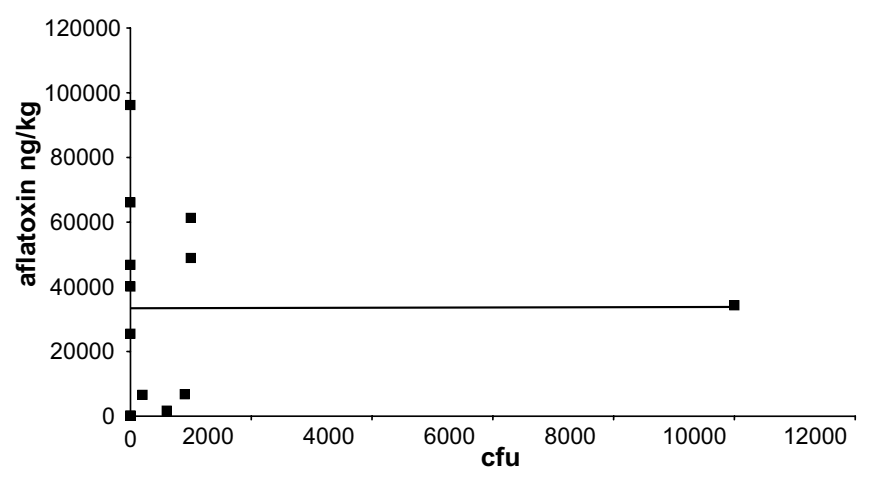

Fig. 2. Total aflatoxins versus A. flavus colony forming units from the chilli samples. The trend line is indicated in unbroken black.

\section{Results}

The concentrations of aflatoxins are presented in Table 1 with details of $A$. flavus colony forming units (cfu). Fig. 1 illustrates the aflatoxins concentrations per sample. The highest value was $93.00 \mu \mathrm{g} \mathrm{kg}^{-1}$ of aflatoxin $\mathrm{B}_{1}$. A direct relationship between aflatoxin $B_{1}$ and aflatoxin $B_{2}$ was apparent. The mean of all samples was $32.11 \mu \mathrm{g} \mathrm{kg}^{-1}$ and $1.31 \mu \mathrm{g} \mathrm{kg}^{-1}$ of aflatoxin $B_{1}$ and $B_{2}$, respectively. A positive result was obtained for each sample. Ground chilli and the samples obtained from Islamabad had the highest values. The relationship between aflatoxin and A. flavus detection is shown in Fig. 2. Mean values of $37.8 \mu \mathrm{g} \mathrm{kg}^{-1}$ and $54.9 \mu \mathrm{g} \mathrm{kg}^{-1}$ were obtained for ground chilli from which A. flavus was and was not detected, respectively.

\section{Discussion}

Although only 13 samples were analysed, they were obtained directly from Pakistani markets and chosen randomly. There is a lack of information from Pakistan and such data are valuable. The values obtained were very high and could present a direct health risk and an economic liability to farmers if these are typical currently. Obviously, differentiation of natural from unnatural concentrations 
of aflatoxins due to malicious acts is more difficult when the natural levels are high.

A. flavus was isolated occasionally and there appears to be no relationship between aflatoxins and detection of the fungus (Fig. 2). In fact, the relationship for powders is an inverse one. Many fungi which produce mycotoxins can also degrade them under specific conditions (Paterson, Venâncio, \& Lima, 2003), so a direct relationship cannot be assumed with implications for controlling aflatoxins. The plating methods described herein may not detect all the producing fungi, and PCR methodology is increasingly advocated (Paterson, in press-b). Manonmani, Anand, Chandrashekar, and Rati (2005) described such a method ostensibly for A. flavus. However, it would probably also detect exclusively sterigmatocystin producing fungi as the target gene is common to both metabolic pathways (Paterson, in press-b). A considerable overestimation is likely upon occasions, hence casting doubt on reliability generally. Paterson (2006) described a PCR method for the patulin biosynthetic pathway which appears to be specific for patulin producing fungi, and a similarly specific gene is required to be tested for aflatoxigenic fungi (e.g. aflQ (Yu et al., 2004). Finally, a PCR method to detect A. flavus in chilli powder would be more relevant than the one proposed to detect $A$. ochraceus (Anand \& Rati, 2006): A. ochraceus is associated with ochratoxin A production for which there are no regulations for chillies currently in the EU.

The detection of aflatoxins, especially in the absence of fungus, indicates another inherent advantage of undertaking the biochemical analysis: In effect, a historical identification can be accomplished, i.e. aflatoxin-producing fungi must have been present at some stage for aflatoxin to be present. On the other hand, it is (just) conceivable that the toxin "percolated" into the sample from nearby biomass. The direct relationship between aflatoxin $B_{1}$ and $B_{2}$ is interesting and indicates that the environmental conditions for the production of one is/are suitable for the other although the absolute concentrations are quite different. It is noted that no aflatoxin Gs were detected. Another possibility is that aflatoxin was added intentionally, which becomes a possibility in the wake of the new security paradigm (Paterson, in press-a).

The mean value reported previously for aflatoxins in chillies was $5.6 \mu \mathrm{g} \mathrm{kg}^{-1}$ (MAFF, 1994). The levels in the present report were nearly a factor of ten higher. They were similar to the concentrations of more than $30 \mu \mathrm{g} \mathrm{kg}^{-1}$ detected from Indian samples in Reddy et al. (2002) in approximately $9 \%$ of the samples. This compares with $54 \%$ in the present study and indicates a severe problem. Reddy et al. (2001) present similar data to Reddy et al. (2002). The conclusion is that a more comprehensive survey is required to assist the farmers in controlling aflatoxins in Pakistan. The high standards which need to be attained if exports are to be accepted are indicated in the recent UK Food Standards Agency (2005) report. The methods for chilli production as described herein appear to be condu- cive to aflatoxin contamination and could be improved with basic training. A hazard analysis critical control point approach would be appropriate for the preparation of chilli in Pakistan, although it is straightforward to suggest some improvements a priori. Such HACCP protocols exist for controlling mycotoxins in a limited number of other commodities (FAO, 2003; Paterson, in press-a; Paterson, in press-b; Paterson, 2006). Finally, some initial basic procedures are (a) protection from water, (b) a careful removal of chillies contaminated with fungus (see discussion above), and (c) the use of good quality pods to produce powder.

In conclusion, high levels of aflatoxin $\mathrm{B}_{1}$ were detected from chilli powder which may be controlled by adopting uncomplicated procedures.

\section{Acknowledgements}

R.R.M. Paterson is funded by grant SFRH/BPD/14923/ 2004 from Fundação para a Ciência e a Tecnologia, Portugal. M.J. Nagler, associate of the National Resources Institute, Chatham Maritime, UK, analysed the samples for aflatoxins under contract.

\section{References}

Anand, S., \& Rati, E. R. (2006). An enzyme-linked immunosorbent assay for monitoring of Aspergillus ochraceus growth in coffee powder, chilli powder and poultry feed. Letters in Applied Microbiology, 42(1), $59-65$.

Bhat, R. V. (1988). Mould deterioration of agricultural commodities during transit: problems faced by developing countries. International Journal of Food Microbiology, 7(3), 219-225.

CAST (2003). Mycotoxins: Risks in plant, animal, and human systems. Council for Agricultural Science and Technology, Ames, IA. Available from http://www.cast-science.org/cast/pub/Mycotoxins.pdf.

FAO (2003). Manual on the application of the HACCP system in mycotoxin prevention and control (online). FAO Food and Nutrition Papers no. 73. Available from http://www.fao.org/DOCREP/005/ Y1390E/y1390e00.htm. (14/1/06).

MAFF (1994). Survey of aflatoxins in herbs and spices. Food Surveillance Information Sheet No. 22, UK.

Manonmani, H. K., Anand, S., Chandrashekar, A., \& Rati, E. R. (2005). Detection of aflatoxigenic fungi in selected food commodities by PCR. Process Biochemistry, 40(8), 2859-2864.

PARC (1996). National Master Agricultural Research Plan - 1996-2005. PARC, MINFAL, Islamabad, Pakistan

Paterson, R. R. M. (2006). Primers from the isoepoxydon dehydrogenase gene of the patulin biosynthetic pathway to indicate critical control points for patulin contamination of apples. Food Control, (17), 741-744.

Paterson, R. R. M. (in press-a). Fungi and fungal toxins as weapons. Mycological Research.

Paterson, R. R. M. (in press-b). Identification and quantification of mycotoxigenic fungi by the PCR. Process Biochemistry.

Paterson, R. R. M., Venâncio, A., \& Lima, N. (2003). Mycotoxins - the experience and expertise of Micoteca da Universidade do Minho. In Biological Resource Centres and the use of microbes, European Culture Collections' Organisation XXII (pp. 217-233). Braga, Portugal Micoteca da Universidade do Minho.

Ravi Kiran, D., Narayana, K. J. P., \& Vijayalakshmi, M. (2005). Alfatoxin $\mathrm{B}_{1}$ production in chillies (Capsicum annum $\mathrm{L}$.) kept in cold stores. African Journal of Biotechnology, 4(8), 791-795.

Reddy, S. V., Kiran Mayi, D., UmaReddy, U., Thitumala-Devi, K., \& Reddy, D. V. R. (2001). Aflatoxins $B_{1}$ in different grades of chillies 
(Capsicum annum L.) in India as determined by indirect competitiveELISA. Food Additives and Contaminants, 18(6), 553-558.

Reddy, D. V. R., Therumala-Devi, K., Reddy, S. V., Walinger, F., Mayo, M. A., Rami Devi, K., et al. (2002). Estimation of aflatoxin levels in selected foods and feeds in India. In Food safety management in developing countries (pp. 1-4). Montpellier, France.

Shamshad, S. I., Zuberi, R., \& Qadir, R. B. (1985). Microbiological studies on some commonly used spices in Pakistan. Pakistan Journal of Science and Industrial Research, 28, 395-399.

Smith, J., Hamid Makhdum, A., \& Ahmad, I. (2000). Evaluation of preand post-harvest disease and pest constraints of chilli reducing yield and quality in the primary chilli growing regions of Pakistan. (p. 47) CABI Bioscience, Wallingford.

UK Food Standards Agency (2005). Food Survey Information Sheet 73/ 05.

Venâncio, A. \& Paterson R. R. M. (in press). The challenge of mycotoxins. In Food safety, a case study approach, Springer.

Yu, J., Chang, P.-K., Ehrlich, K. C., Cary, J. W., Bhatnagar, D., Cleveland, T. E., et al. (2004). Clustered pathway genes in aflatoxin biosynthesis. Applied and Environmental Microbiology, 70(3), 1253-1262. 